\title{
Muscle power after glucose-potassium loading in undernourished patients
}

\author{
S T F CHAN, S J McLAUGHLIN, G A PONTING, J BIGLIN, H A F DUDLEY
}

\begin{abstract}
The force-frequency characteristics and maximal relaxation rate of the adductor pollicis muscle were measured before and after 48 hours of intravenous loading with glucose $(104.5 \mathrm{~kJ}$ ( $25 \mathrm{kcal}) /$ $\mathrm{kg} / 24 \mathrm{~h}$ ) and potassium $(20 \mathrm{mmol}(\mathrm{mEq}) / 500 \mathrm{ml}$ glucose $)$ in eight undernourished patients about to undergo surgery. Both variables of skeletal muscle performance, which were depressed when compared with data from 100 healthy volunteers, improved significantly after glucose-potassium loading. The improvement was accompanied by restoration of muscle glycogen values and return of respiratory exchange ratios towards unity.

These results imply that if muscle power is a yardstick for preoperative nutritional rehabilitation then a simple regimen of energy-electrolyte repletion may be cost effective in preparing undernourished patients for major surgery.
\end{abstract}

\section{Introduction}

The function of skeletal muscles has recently been increasingly studied in relation to nutritional rehabilitation in undernourished patients. ${ }^{1.3}$ Results suggest that the contractile properties of skeletal muscle reflect small and early changes in nutritional state before those detectable by standard methods of nutritional assessment. Russell et al showed that obese subjects undergoing a two week period of hypocaloric feeding $(1.67 \mathrm{MJ}(400 \mathrm{kcal}) /$ day $)$ had abnormal muscle function, which was further exacerbated by a two week fast. ${ }^{4}$ All objective tests of muscle function returned towards normal after two weeks of refeeding $(4 \cdot 18 \mathrm{MJ}(1000 \mathrm{kcal}) /$ day $)$. Similarly, in anorectic patients, variables of muscle function improved within four to eight weeks of oral refeeding. ${ }^{5}$ In a small group of undernourished patients with various gastrointestinal disorders skeletal muscle performance was significantly improved after four weeks of conventional total parenteral nutrition. ${ }^{\prime}$

None of the above studies, however, were performed in controlled circumstances of energy and water-electrolyte repletion. We report here our studies on the effects of a simple glucose-potassium regimen on muscle function in undernourished patients.

\section{Patients and methods}

The basic apparatus for objective testing of muscle function is that originally developed by Merton ${ }^{6}$ and modified by Edwards $\mathrm{et} \mathrm{al}^{7}$ for study of the contractile characteristics of the intact adductor pollicis muscle. We redesigned this and developed a system to produce a fairly inexpensive and portable apparatus incorporating a microprocessor that permits bedside testing of immobilised patients. ${ }^{8}$ The ulnar nerve is electrically stimulated at the wrist by a series of frequencies and the force of contraction so generated measured in the adductor pollicis muscle by means of a loop around the interphalangeal joint of the thumb. The tests were preceded by warming the

Academic Surgical Unit, St Mary's Hospital, London W2 1PG

S T F CHAN, PHD, FRCS, senior lecturer and honorary consultant surgeon

S J MCLAUGHLIN, FRACS, FRCS, research fellow

G A PONTING, FRCS, research fellow

J BIGLIN, AMIBIOL, senior technician

H A F DUDLEY, CHM, FRCS, professor of surgery

Correspondence to: $\mathrm{Mr}$ Chan. hand to $40^{\circ} \mathrm{C}$ with an electric pad (Gillette heat wrap), and electromyograms of the adductor pollicis were recorded (Medelec MS92a) to ensure supramaximal stimulations. The effects of post-tetanic potentiation were standardised by a fixed order of testing.

The force-frequency characteristics and maximal relaxation rate of the adductor pollicis muscle were studied in 100 healthy volunteers $(50$ men, 50 women) aged 19-83 (median 29) to establish a normal database for comparison with the undernourished patients.

We studied eight patients about to undergo surgery who were judged clinically to be undernourished, with a weight loss of greater than $10 \%$ (range 10-18\%). Four patients were suffering from dysphagia as a consequence of oesophageal stricture, one had a carcinoma of the stomach, one

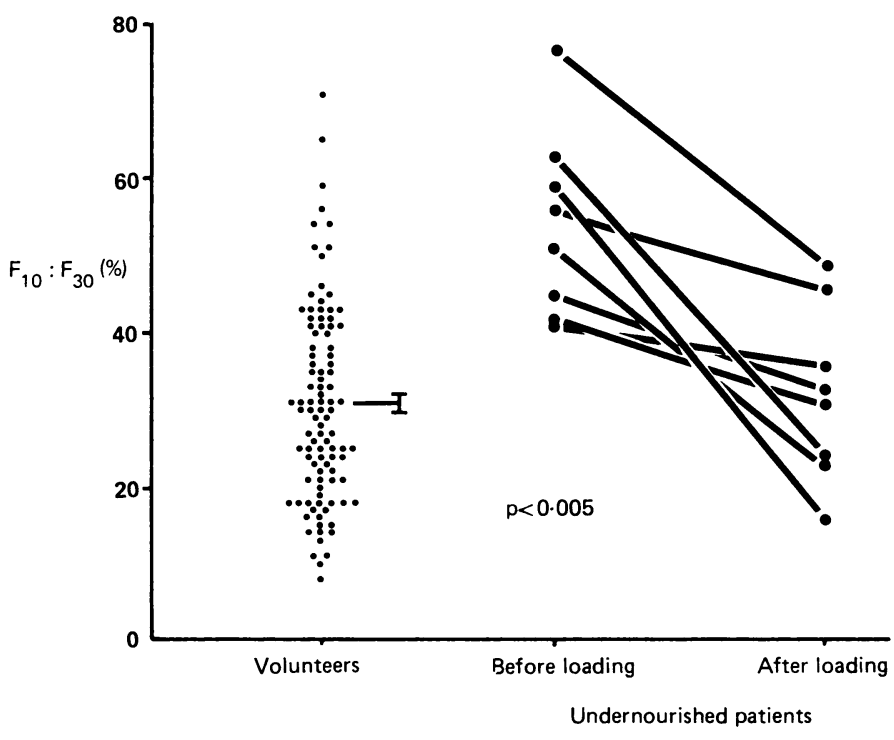

FIG 1-Force-frequency ratio $\left(\mathrm{F}_{10}: \mathrm{F}_{30}\right)$ before and after glucose-potassium loading compared with values (and mean (SEM)) in 100 volunteers.

had a carcinoma of the colon, and two had intestinal obstruction. All patients underwent muscle function tests, indirect calorimetry by the canopy hood method to calculate respiratory exchange ratio, ${ }^{9}$ and percutaneous biopsy of the quadriceps femoris (Allendale needle) for measurement of muscle glycogen values ${ }^{10}$ before and after glucose-potassium loading for 48 hours. Glucose loading was provided by intravenous infusion of $20 \%$ dextrose, supplying $104.5 \mathrm{~kJ}(25 \mathrm{kcal}) / \mathrm{kg} / 24 \mathrm{~h}$. Potassium $20 \mathrm{mmol} /(\mathrm{mEq})$ was added to each $500 \mathrm{ml}$ of the infusion.

Statistical comparisons were made with Student's $t$ test (paired and unpaired as appropriate) for normally distributed data. Informed consent was obtained and the study approved by the local ethics committee.

\section{Results}

Force-frequency characteristics (fig 1)-The maximum force measured at stimulation of $10 \mathrm{~Hz}$ was expressed as a percentage of that measured at stimulation of $30 \mathrm{~Hz}$. This value $\left(\mathrm{F}_{10}: \mathrm{F}_{30}\right)$ was significantly increased in the patients (table) and returned towards the normal range after 48 hours of glucose-potassium loading (mean (SEM) in volunteers $31 \cdot 8(2 \cdot 4) \%$ ).

Maximal relaxation rate (fig 2) - After a brief tetanic stimulation $(2 \mathrm{~s})$ at 30 $\mathrm{Hz}$ the maximal relaxation rate of the adductor pollicis muscle was calculated from the maximum slope of the initial phase of relaxation and expressed as percentage force fall $/ 10 \mathrm{~ms}^{7}$ The maximal relaxation rate was slow in all the 


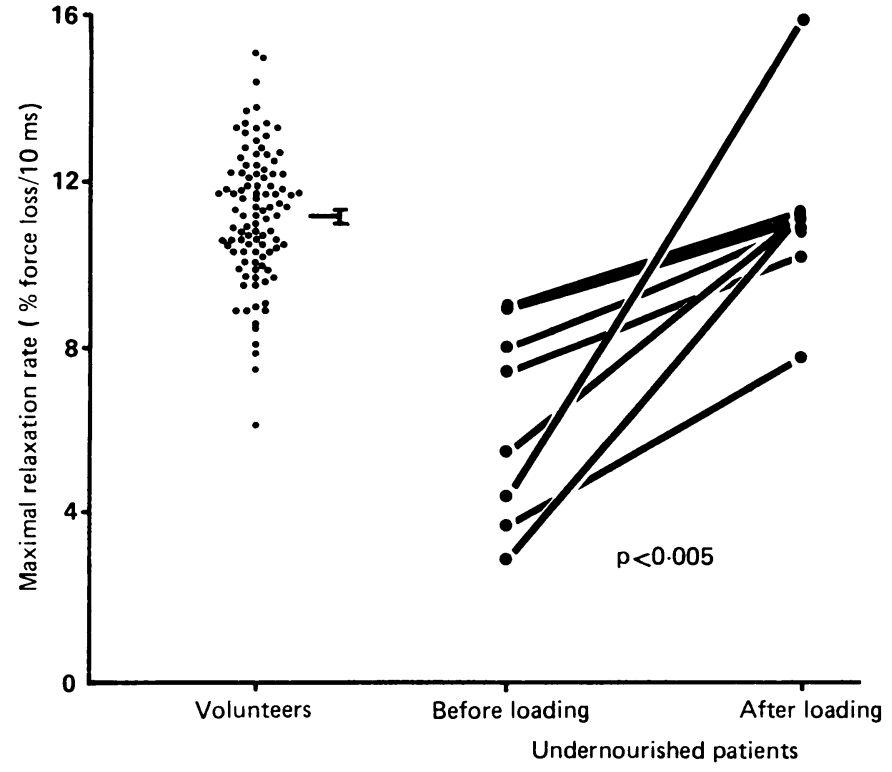

FIG 2-Maximal relaxation rate before and after glucose-potassium loading compared with values (and mean (SEM)) in 100 volunteers.

Mean (SEM) force-frequency characteristics $\left(F_{10}: F_{30}\right)$, maximal relaxation rate, muscle glycogen content, and respiratory exchange ratio before and after glucosepotassium loading

\begin{tabular}{|c|c|c|c|c|}
\hline & $F_{10}: F_{30}(\%)$ & $\begin{array}{c}\text { Maximal } \\
\text { relaxation rate } \\
(\% \text { force fall } / 10 \mathrm{~ms})\end{array}$ & $\begin{array}{c}\text { Glycogen } \\
\text { (mg/g dry } \\
\text { muscle) }\end{array}$ & $\begin{array}{l}\text { Respiratory } \\
\text { exchange } \\
\text { ratio }\end{array}$ \\
\hline $\begin{array}{l}\text { Before } \\
\text { After } \\
\mathrm{p}^{\star}\end{array}$ & $\begin{array}{l}54 \cdot 88(4 \cdot 65) \\
32 \cdot 82(4 \cdot 25) \\
\quad<0.005\end{array}$ & $\begin{array}{c}6.34(0.90) \\
11.39(0.94) \\
<0.005\end{array}$ & $\begin{array}{l}16 \cdot 52(4 \cdot 74) \\
44 \cdot 48(8.92) \\
\quad<0.005\end{array}$ & $\begin{array}{l}0.79(0.02) \\
0.95(0.01) \\
<0.005\end{array}$ \\
\hline
\end{tabular}

${ }^{\star}$ Paired $t$ test.

patients compared with that in the volunteers. After 48 hours of glucosepotassium loading it was significantly increased (table) and closer to the mean in the volunteers $(11 \cdot 2$ (SEM 0.3$) \% / 10 \mathrm{~ms})$.

Muscle glycogen content rose significantly after glucose-potassium loading (table).

Respiratory exchange ratios approached unity after loading (table).

\section{Discussion}

Over the past few years there have been several reports that objective functional changes in muscle contraction are more sensitive than changes in the composition of the body in detecting undernutrition and monitoring repletion..$^{1.5}$ The precise mechanisms of muscle dysfunction in relation to nutritional state remain unclear, although various inferences have been made regarding changes in ultrastructure and intracellular composition. ${ }^{11}$ None of these studies, however has been performed under controlled circumstances of energy and water-electrolyte repletion.

Our study in eight patients before surgery who were judged clinically to be undernourished showed that abnormal functional variables in muscle contraction may be reversed by 48 hours of infusion of glucose, water, and potassium. Although we did not perform conventional studies of the composition of the body in these patients, it is clear from our previous studies ${ }^{12}$ and from direct measurement of glycogen in these patients that glycogen had been stored in their muscles together with the necessary potassium. The concomitant increase in respiratory exchange ratios implied a change to glucose substrate oxidation.

Although the effect of short term (seven to 10 days) preoperative nutritional support on postoperative morbidity and mortality is conflicting, ${ }^{13-15}$ its major effect in depleted patients seems to be the $\mathbb{\Phi}$ restoration of liver and muscle glycogen stores. ${ }^{16}{ }^{17}$ We showed in m this study that abnormal variables of muscle function can be improved by a short course of high carbohydrate and potassium $\vec{F}$ loading with restoration of muscle glycogen content. This implies $\stackrel{0}{\rightarrow}$ that if muscle power can be regarded as a yardstick for preoperative nutritional rehabilitation then a simple regimen of energy-electrolyte $\overline{\overline{\mathrm{S}}}$ repletion may be cost effective in preparing undernourished patients for major surgery. Further studies are needed to elucidate the bioenergetics of glucose-potassium loading on muscle function. is

We gratefully acknowledge support of the Wellcome Trust.

\section{References}

1 Lopes J, Russell DMcR, Whitwell J, Jeejeebhoy KN. Skeletal muscle function in malnutrition. Am f Clin Nutr 1982;36:602-10.

2 Russell DMcR, Atwood HL, Jeejeebhoy KN. Nitrogen versus muscle calcium in the genesis of the abnormal muscle in malnutrition. Journal of Parenteral and Enteral Nutrition 1985;9:415-21.

3 Berkelhammer CH, Leiter LA, Jeejeebhoy KN, Detsky AS, Oreopoulos DG, Uldall PR. Skeletal muscle function in chronic renal failure: an index of nutritional status. Am $\mathcal{J}$ Clin Nutr 1985;42:845-54.

4 Russell DMCR, Leiter LA, Whitwell J, Marliss EB, Jeejeebhoy KN. Skeletal muscle function during hypocaloric diets and fasting: a comparison with standard nutritional assessment parameters. Am f Clin Nutr 1983:37:133-8.

5 Russell DMcR, Prendergast PJ, Darby PL, Garfinkel PE, Whitwell J, Jeejeebhoy KN. A $N$ comparison between muscle function and body composition in anorexia nervosa: the effects of refeeding. Am $\mathcal{F}$ Clin Nutr 1983;38:229-37.

6 Merton A. Voluntary strength and fatigue. $\mathcal{J}$ Physiol 1954;123:553-64.

7 Edwards RHT, Young A, Hoskings GP, Jones DA. Human skeletal muscle function: description of tests and normal values. Clinical Science and Molecular Medicine 1977;52:283-90.

8 Chan STF, Ford D, McLaughlin SJ, Neame SJ. Computerized displacement transducer $\vec{\bullet}$ for quantifying muscle weakness and fatigue in surgical patients. Proceedings of the Physiological Society. 7 Physiol 1986;374:13P.

9 Lindmark L, Ekman L, Lundholm K. A simplified technique for measurements of energy expenditure and substrate oxidation in man. Clin Physiol 1985:5:377-45.

10 Harris RC, Hultman E, Nordesjo L-O. Glycogen, glycolytic intermediates and high energy phosphates. Determination in biopsy samples of musculus quadriceps femoris man at rest. Methods and variance of values. Scand 7 Clin Invest 1974;33:109-20.

11 Russell DMcR, Atwood HL, Whittaker JS, et al. The effects of fasting and hypocaloric diets on the functional and metabolic characteristics of rat gastrocnemius muscle. Clin Sci 1984;67:185-94.

12 Chan STF, Johnson AW, Moore MH, Kapadia CR, Dudley HAF. Early weight gain and $\overrightarrow{\overline{\mathrm{O}}}$ glycogen obligated water during nutritional rehabilitation. Hum Nutr Clin Nutr $1982 ; 36 \mathrm{c}: 223-32$

13 Heatley RV, Williams RHP, Lewis MH. Preoperative intravenous feeding-a controlled trial. Postgrad Med 1979;55:541-5.

14 Mullen JL, Buzby GP, Matthews DC, Smale BF, Rosato EF. Reduction of operative morbidity and mortality by combined preoperative and postoperative nutritional support. Ann Surg 1980;192:604-13.

15 Muller JM, Brenner U, Dienst C, Pichlmaier H. Preoperative parenteral feeding in patients with gastrointestinal carcinoma. Lancet 1982;1:68-71.

16 Thomas RJS. The modifying effect of nutritional intake on post-traumatic depletion in hepatic glycogen in rats. Surgery 1980;87:539-44.

17 Sandstedt S, Lennmarken C, Symreng T, Vinnars E, Larsson J. The effect of preoperative total parenteral nutrition on energy-rich phosphates, electrolytes and free amino acids in skeletal muscle of malnourished patients with gastric carcinoma. $\mathrm{Br} \mathcal{F}$ Surg 1985;72:920-4.

(Accepted 14 August 1986)

\section{Correction}

Splenic irradiation in treating warm autoimmune haemolytic anaemia

We regret that an error occurred in this paper by Dr H Markus and Dr J C Forfar (4 October, $p$ 839). The fifth sentence of the second paragraph of the case report should have read: "Sixty days after admission a blood film showed appearances similar to those after splenectomy, with Howell-Jolly bodies." 